This item was submitted to Loughborough's Research Repository by the author.

Items in Figshare are protected by copyright, with all rights reserved, unless otherwise indicated.

\title{
A notched hand wearable ultra wideband w printed monopole antenna for sporting activities
}

PLEASE CITE THE PUBLISHED VERSION

http://dx.doi.org/10.1109/LAPC.2008.4516950

PUBLISHER

Loughborough University (@ IEEE)

VERSION

AM (Accepted Manuscript)

LICENCE

CC BY-NC-ND 4.0

\section{REPOSITORY RECORD}

Ma, Lei, R.M. Edwards, and W.G. Whittow. 2019. "A Notched Hand Wearable Ultra Wideband W Printed Monopole Antenna for Sporting Activities". figshare. https://hdl.handle.net/2134/10012. 
This item was submitted to Loughborough's Institutional Repository (https://dspace.lboro.ac.uk/) by the author and is made available under the following Creative Commons Licence conditions.

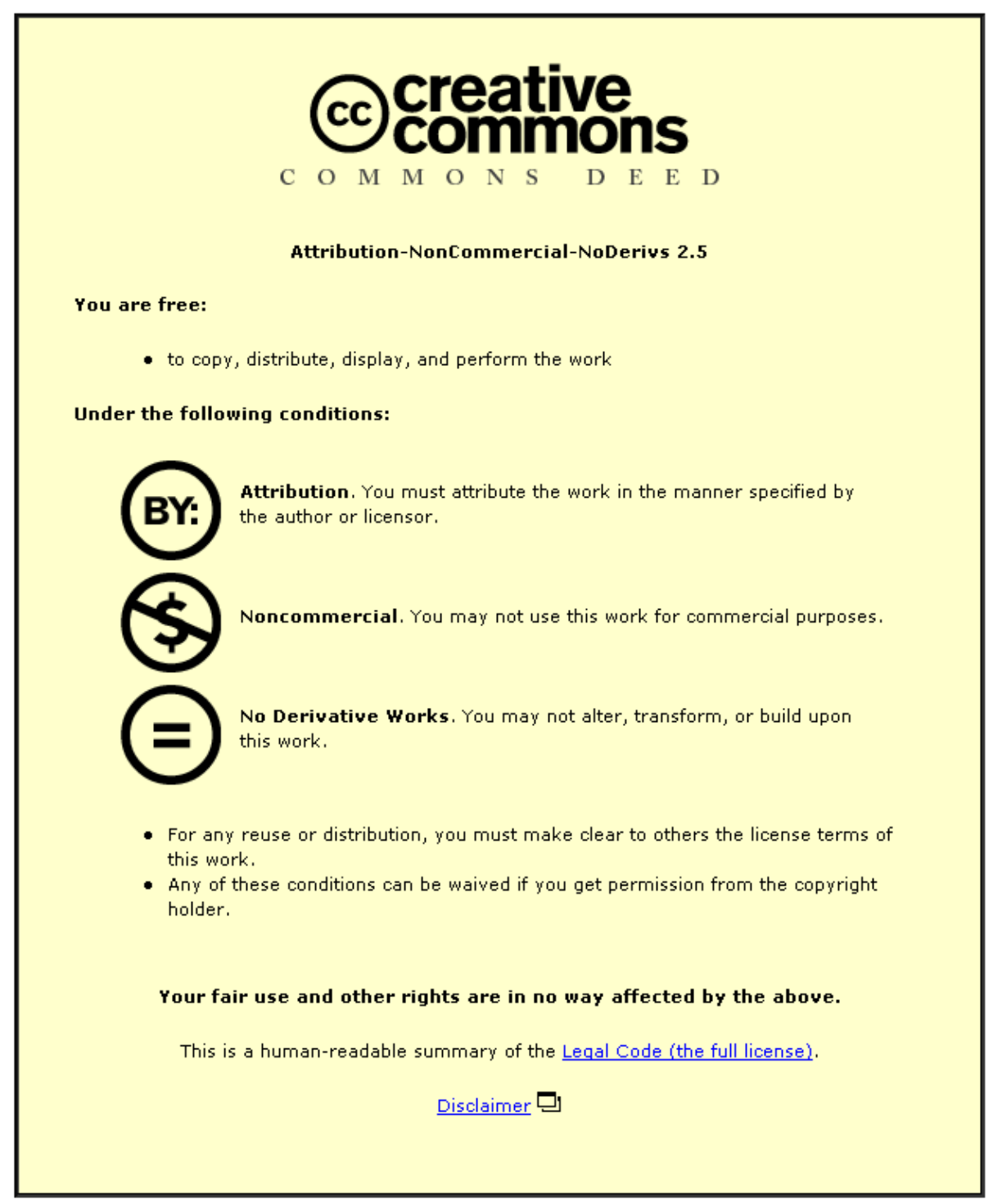

For the full text of this licence, please go to: http://creativecommons.org/licenses/by-nc-nd/2.5/ 


\title{
A NOTCHED HAND WEARABLE ULTRA WIDEBAND W PRINTED MONOPOLE ANTENNA FOR SPORTING ACTIVITIES
}

\author{
Lei Ma ${ }^{(1)}$, R. M. Edwards ${ }^{(1)}$ and W.G. Whittow ${ }^{(1)}$ \\ ${ }^{(1)}$ Department of Electronic \& Electrical Engineering, Loughborough University, \\ Leicestershire, LE11 3TU. UK.
}

\author{
Email: L.Ma@Iboro.ac.ukEmail: R.M.Edwards@lboro.ac.uk Email: \\ W.G.Whittow@lboro.ac.uk
}

\begin{abstract}
:
This paper proposes a flexible wearable ultra-wideband antenna suitable for 802.15.3a WPAN applications. The design contains a notch at $5.2 \mathrm{GHz}$ for HIPERLAN compatibility. A novel neoprene $\odot$ substrate is introduced in this paper. Measured results are included for "Antenna on skin" and "Antenna on a hand glove" for return loss and far-field patterns.
\end{abstract}

\section{Introduction}

Ultra-wideband radio (UWB) has been proposed as a technology suitable for wireless body area networks. UWB will offer a high data rate, short range low power channel within a tightly specified range of frequencies. Several interesting designs have been proposed [1, 2]. Antennas with stop bands have also been researched at WLAN 5.2 $\mathrm{GHz}$ band $[3,4]$. Allied with this has been a growing interest in wearable computer systems and so called "smart clothing" in which computers and radios made of flexible circuits are embedded into garments. For example a wearable Half-Disk UWB antenna made of several flexible conductive materials is introduced in [5], and another example of a UWB textile antenna designed for body area network is presented in [6].

On-body antennas placed on the skin or more commonly integrated into clothing, and are widely used in many areas. In this paper we do not consider the related area of radio frequency identity tags (RFIDs). For wearable antennas integrated into clothing microstrip antennas have been preferred among the candidates [7, 8]. In such uses microstrip antennas with flexible conductors and substrates are needed and this has led to an increased demand for electrical technical textiles (ETTs). Microstrip antennas [9] have some significant advantages for onbody wearables the three major ones being their ease of construction, their cost effectiveness and an associated metallic groundplane that when used between the body and the radiating element/s can significantly reduce energy absorbed by the body. However, microstrip antennas tend to low bandwidths and may need to be relatively large if they are to be robust against perturbation by the body. Another type of planar antenna is the printed monopole [10]. These can be made with small footprints, have shown wide multi-band performance, and can be made to have limited Omni-directional properties their radiation patterns which is desirable in wearable antennas. Typically for flexible and wearable antennas the substrate materials chosen have been textiles or plastics. Textiles tend to low relative permittivity (<2) and suffer somewhat from trapped air which may have variable electrical characteristics due to water content. Plastics, for example polypropylene, are not well suited to wearing close to the skin and also have relatively low permittivity $(<2)$. Neoprene [11] is a material commonly seen in scuba diving suits but more recently in sporting attire. It is durable, has good thermal properties and is generally consistent in density. It also has a permittivity greater than 4 . It is a good choice for wearable antennas. In this paper, we will present a wearable printed monopole antenna which covers the UWB frequency band $3.1 \mathrm{GHz}-10.6 \mathrm{GHz}$ and has a notch at WLAN5GHz band. Results show that different loss properties of the substrate have a very important impact on the resonant performance especially at the notch band. Therefore, a material with low loss and water resistant properties would be very important for wearable UWB antennas with a notch function. Results of return loss and far-field radiation pattern are given here. 


\section{Antenna Design}

Our novel antenna is W shaped and printed onto Neoprene and fed with a 50ohm microstrip. It is shown in Fig. 1.

The feed is fed against a groundplane but the active elements are not and the antenna therefore can be classed as a type of printed monopole. Impedance matching was achieved by symmetrical cut-offs at the bases of the two outer W legs. For providing impedance matching, the dimension of the two cut off corners is very important. The stop band characteristics are associated with the tuning of the central leg of the antenna. The antenna is built on a $1.5 \mathrm{~mm}$ thick compressed Neoprene $\odot$. The properties of the sample were measured by a split post dielectric resonator and the relative permittivity was found to be 5.2 with 0.03 loss tangent at $1.9 \mathrm{GHz}$. However, since a wide-band dielectric measurement was not available we have assumed an average permittivity of 4.5 over the range of the antenna. Our pre-build simulations were done using the EM simulator Microstripes.

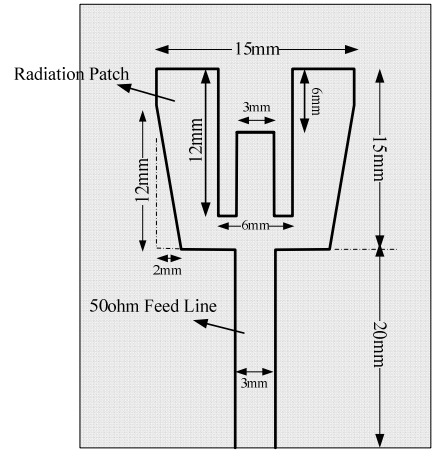

(a) Top View

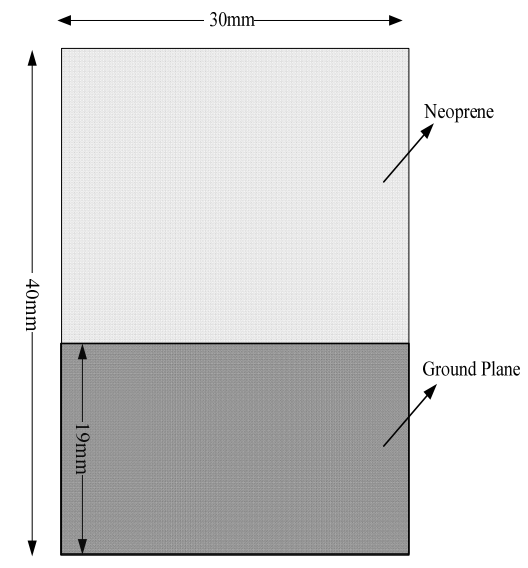

(b) Bottom View

Fig.1 Dimensions of the wearable UWB antenna

\section{Results}

\section{Simulations}

After simulated tuning of a prototype antenna an initial experiment was done to estimate the influence of loss in the dielectric substrate. The results were obtained to help judge the effect of material variability on the $Q$ of our proposed HIPERLAN notch. The conductivity of the substrate was varied and the results of return loss are shown in Fig.2 (a). The figure shows that the antenna covers the UWB band and a notch can be found at WLAN5GHz band for the low loss antennas. Note that an improved notch function can be achieved by changing the dimensions of the slots. Two are needed to achieve symmetry and they are capacitive in nature. In general for each spot frequency the antenna efficiency falls off as a negative exponential with increasing conductivity. At frequencies around the notch the antenna is generally less efficient, which is shown in Table 1 . Note that Neoprene is not highly specified (usually specified for thermal properties), and for this application and all samples came from the same batch of material.

\section{Measurements}

An antenna was made (Fig. 1), and measurements were done to study perturbation from a human hand. The volunteer was a 30 year old male who weighed $120 \mathrm{~kg}$. For return loss the antenna was measured in free space, on the back of the right hand with the groundplane directly in contact with the skin and with the antenna on back of a woollen glove also worn on the right hand. The position of the hand in relation to the body was kept as constant as possible however the room was not screened. Results show that the isolation effect of the glove is useful. When directly mounted on the back of the hand, this antenna has reduced performance including the absence of the frequency cut off. To measure the radiation patterns in an anechoic chamber, a 1.4kg leg joint from an animal was used to simulate the effects of a human hand. For the on skin measurement the antenna was place directly onto the flesh. For the on-glove measure a $2.5 \mathrm{~mm}$ layer was inserted between the antenna's ground plane and the flesh. Although monopole antennas show relatively omni-directional radiation patterns in free 
space, the main lobe of this antenna was seen to be away from the flesh. The results at $3 \mathrm{GHz}$ and $6 \mathrm{GHz}$ are shown in Fig.3.

Return Losses in Free Space

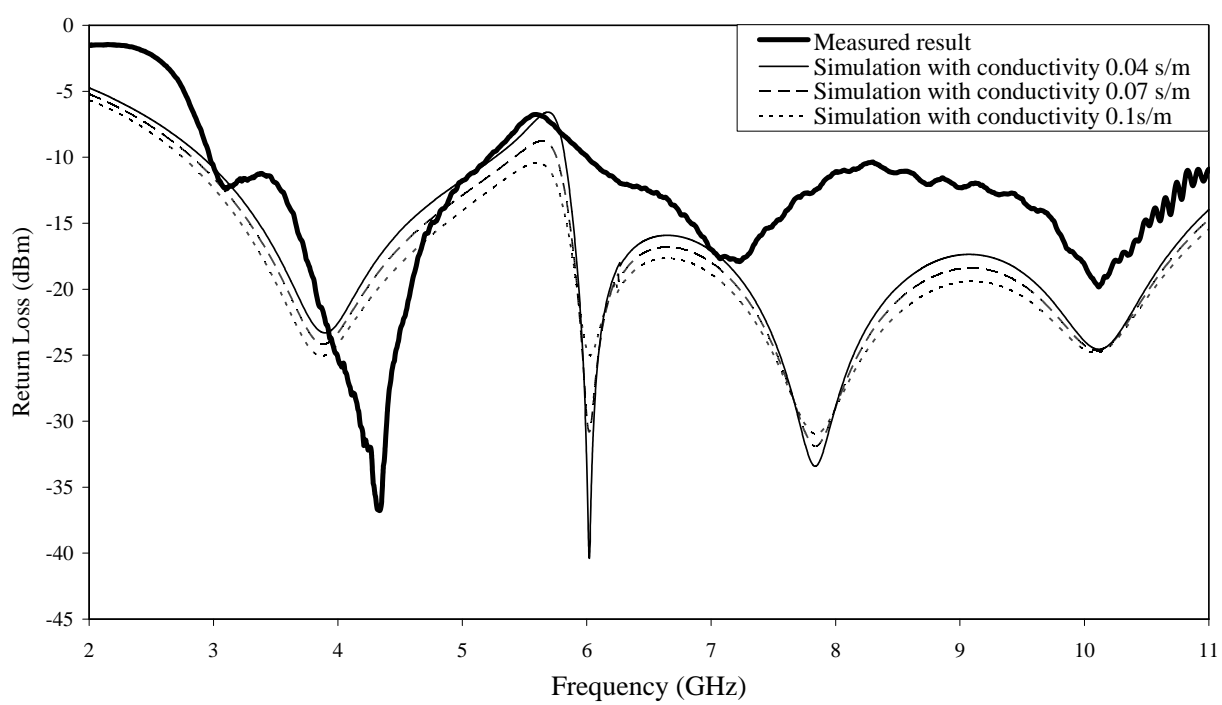

(a)

Return Losses on Hand

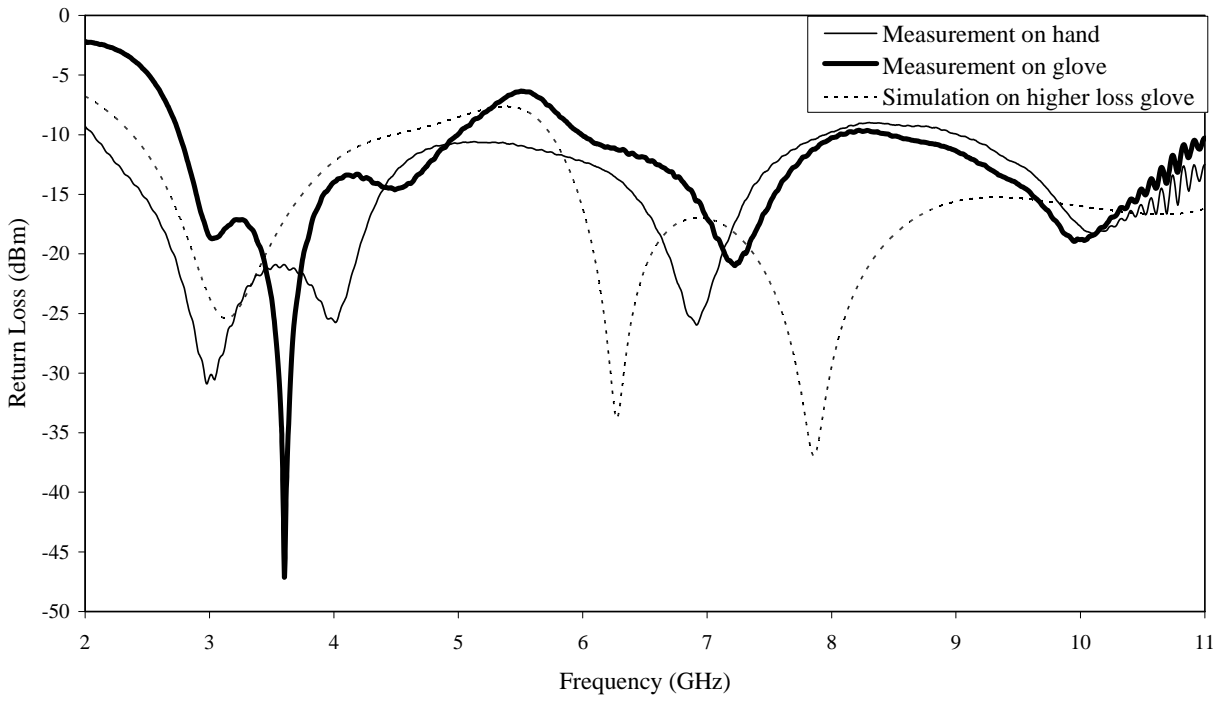

(b)

Fig.2. Comparison of Return Losses in free space and on hand

\begin{tabular}{|c|c|c|c|c|c|}
\hline Conductivity $\mathrm{S} / \mathrm{m}$ & $4 \mathrm{GHz}$ & $5.5 \mathrm{GHz}$ & $6 \mathrm{GHz}$ & $8 \mathrm{GHz}$ & $10 \mathrm{GHz}$ \\
\hline 0.01 & 93.43 & 58.5 & 91.8 & 94.9 & 94.7 \\
\hline 0.04 & 80.13 & 47.7 & 74.3 & 83.1 & 83.3 \\
\hline 0.07 & 69 & 40.7 & 61.4 & 72.7 & 73.3 \\
\hline 0.1 & 59.7 & 36 & 51.7 & 63.6 & 64.5 \\
\hline 0.3 & 24.6 & 18.8 & 21.35 & 26.2 & 27.4 \\
\hline 0.5 & 11.1 & 9.5 & 9.9 & 11.1 & 12 \\
\hline
\end{tabular}

Table 1. Comparison of antenna efficiency (\%) with varied conductivity 


\section{Conclusions}

A new wearable UWB antenna with a notch function at WLAN $5 \mathrm{GHz}$ has been introduced. Simulations show that low loss non-conductive substrates maintain the antenna characteristics to allow a frequency notch. Measurements on-body show a general lowering in frequency on the resonances for the antenna when compared with free space versions. Neoprene is a good choice for wearable antennas and is particularly suitable for sporting activates and some specialist environments. The glove plays a very important role, reducing the coupling between the antenna and the hand and this concludes to having a layer of dielectric beneath the groundplane of on-body antennas. Our future work will include a better characterisation of the properties of Neoprene $($ and the incorporation of a larger phantom for human body perturbation.

\section{References}

[1] Low, Z.N.; Cheong, J.H.; Law, C.L.; "Low-cost PCB antenna for UWB applications”, Antennas and Wireless Propagation Letters, Vol. 4, Page(s):237 - 239, 2005

[2] Taeyoung Yang; Davis, W.A.; "Planar half-disk antenna structures for ultra-wideband communications", Antennas and Propagation Society International Symposiu, 2004. IEEE, Vol.3, Page(s):2508 - 2511, 20-25 June 2004

[3] Yongjin Kim; Do-Hoon Kwon; "Planar ultra wide band slot antenna with frequency band notch function", Antennas and Propagation Society International Symposium, 2004. IEEE, Vol.2, Page(s):1788 - 1791, $20-25$ June 2004

[4] Kerkhoff, A.; Hao Ling; "A parametric study of band-notched UWB planar monopole antenna", Antennas and Propagation Society International Symposium, 2004. IEEE, Vol.2, Page(s):1768 - 1771, 20-25 June 2004

[5] Taeyoung Yang; Davis, W.A.; Stutzman, W.L.; "Wearable ultra-wideband half-disk antennas", Antennas and Propagation Society International Symposium, 2005 IEEE, Vol. 3A, Page (s):500 - 503, 3-8 July 2005

[6] Klemm, M.; Troester, G.; "Textile UWB Antennas for Wireless Body Area Networks", Antennas and Propagation, IEEE Transactions on, Volume 54, Issue 11, Part 1, Page(s):3192 - 3197, Nov. 2006

[7] Salonen, P.; Hurme, L., "A novel fabric WLAN antenna for wearable applications," Antennas and Propagation Society International Symposium, 2003. IEEE, Volume 2, Page(s):700 - 703, 22-27 June 2003 [8] Hertleer, C.; Tronquo, A.; Rogier, H.; Vallozzi, L.; Van Langenhove, L., "Aperture-Coupled Patch Antenna for Integration Into Wearable Textile Systems," Antennas and Wireless Propagation Letters, Volume 6, Page(s):392 - 395, 2007

[9] Ramesh Garg, Prakash Bhartia, Inder Bahl, Apisak Ittipiboon, "Microstrip antenna design handbook", Artech House, 2001.

[10] Pan, B.; Li, R.L.; Papapolymerou, J.; Laskar, J.; Tentzeris, M.M.; "Low-Profile Broadband and DualFrequency Two-Strip Planar Monopole Antennas", Antennas and Propagation Society International Symposium 2006, IEEE, Page (s):2665 - 2668, 9-14 July 2006

[11] Hoagland, H.; Morrow, B.; "Using rainwear as switching jackets: a reasonable solution for electric arc exposure" , Industry Applications, IEEE Transactions on, Volume 36, Issue 5, Page(s):1241 - 1246, Sept.-Oct. 2000 

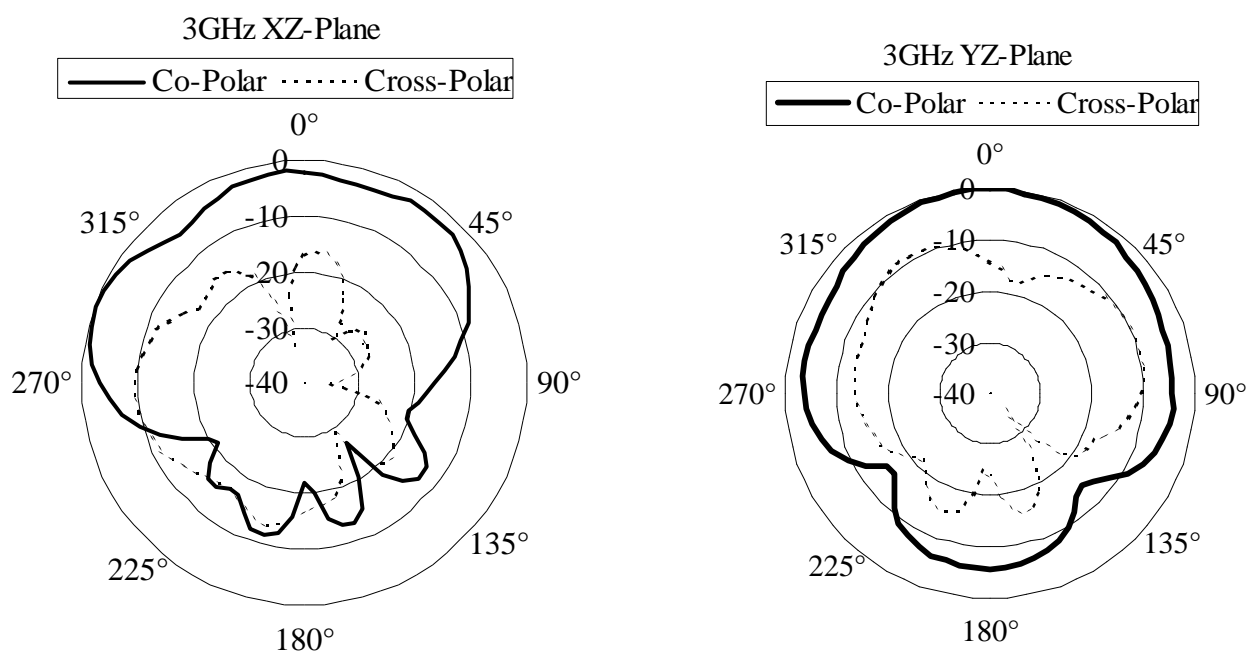

(a)
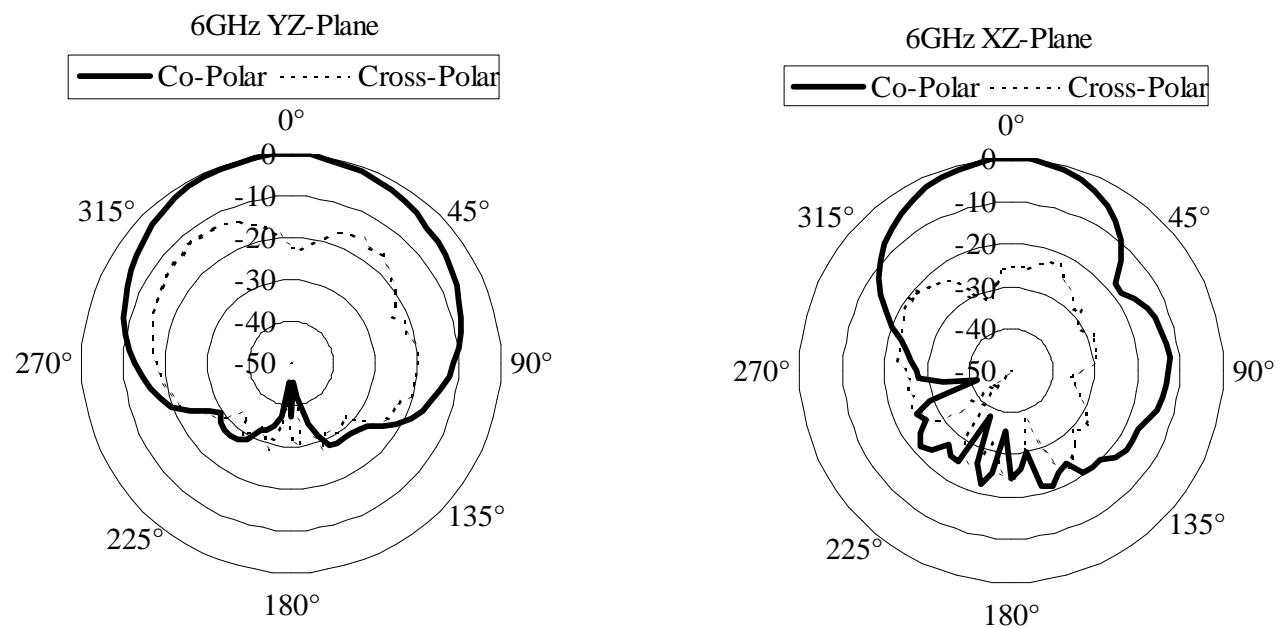

(b)

Fig.3. Measured radiation patterns at $3 \mathrm{GHz}$ and $6 \mathrm{GHz}$ 